\title{
Cowper's Syringocele in Adolescent Male: Case Report
}

\author{
Milena Taskovska and Simon Hawlina
}

\begin{abstract}
Background: Cowper's syringocele is a rare condition, uncommon in the adult population. It is more common in the pediatric population. Patients could be asymptomatic or present with irritative and/or obstructive symptoms. Ultrasonography (US) of perineal region, pelvis MRI, or urethrography are the most often used diagnostic modalities. Surgical treatment is indicated in all symptomatic patients. Endoscopic approach is preferred over open surgery. Unroofing of syringocele with cold knife or holmium yttrium aluminium garnet (YAG) laser is effective treatment.

Case Presentation: A 17-year-old Caucasian male presented at our emergency department with irritative symptoms. US of perineal region showed cystic formation near urethra. Pelvis MRI showed Cowper's gland syringocele. Endoscopic unroofing with holmium YAG laser was performed. Six months postoperatively the patient was asymptomatic and satisfied with the treatment.

Conclusion: Cowper's syringocele is a rare condition. Urologist should consider this condition in pediatric and adolescent patients with irritative and/or obstructive symptoms. Pelvis MRI and perineum US are the main diagnostic tools. Surgical treatment is effective. Endoscopic approach is preferred. Open surgery is indicated in complicated cases and in cases when endoscopic treatment fails.
\end{abstract}

Keywords: Cowper's gland, syringocele, endoscopic unroofing, adolescent, LUTS

\section{Introduction and Background}

C OWPER's GLANDS ARE PAIRED, accessory sexual organs situated within the urogenital diaphragm (the main glands), and in bulbospongial tissue (the accessory glands). ${ }^{1,2}$ The main glands form ducts (about $2.5 \mathrm{~cm}$ long) through which the secretion is excreted into the bulbar urethra. ${ }^{3}$ The main Cowper's duct enters the ventral surface of the bulbar urethra near the midline by piercing the spongiosum. ${ }^{1}$ Accessory ducts can either enter the urethra directly or indirectly through the main duct. ${ }^{1}$ Secretion of Cowper's glands contributes to semen coagulation and urethral lubrication. ${ }^{1}$

Cowper's syringocele refers to cystic dilation of the main duct. ${ }^{1}$ These lesions were described and classified by Meizels into four groups:

(1) simple syringocele - a minimally dilated duct,

(2) perforate syringocele-bulbous duct drains into the urethra and appears as a diverticulum,

(3) imperforate syringocele-bulbous duct resembles a submucosal cyst and appears as a radiolucent mass, and
(4) ruptured syringocele with membrane remaining in the urethra after a dilated duct ruptures. ${ }^{1,4}$

Lesions of the Cowper's gland are congenital, found mainly in pediatric population. ${ }^{1,2}$ Data about incidence are scarce. ${ }^{1,3}$ Incidence in boys is about $1.5 \% .^{1}$ Cowper's syringocele is rare in adults. ${ }^{1,3}$ In such cases, urethral duplication and urethral diverticulum should also be considered. In young adults presenting with postmicturition dribbling and low urinary tract symptoms, Cowper's syringocele should be considered. ${ }^{1}$ Surgical treatment is indicated in all symptomatic patients. ${ }^{1,3}$ Endoscopic unroofing is treatment of choice. ${ }^{1}$ Holmium yttrium aluminium garnet (YAG) laser can be used for this purpose.

This article presents a case report of an adolescent male with Cowper's syringocele treated at our department.

\section{Presentation of Case}

A 17-year old male Caucasian presented at our emergency department (ED) for urinary incontinence. He had a 2-year

Department of Urology, University Medical Centre Ljubljana, Ljubljana, Slovenia.

(C) Milena Taskovska and Simon Hawlina 2017; Published by Mary Ann Liebert, Inc. This is an Open Access article distributed under the terms of the Creative Commons Attribution License, which permits unrestricted use, distribution, and reproduction in any medium, provided the original work is properly cited. 
history of urinary incontinence and postvoid dribbling. $\mathrm{He}$ denied burning pain during micturition and hematuria. Two years ago he had been treated for urinary tract infection (UTI). He was healthy, with no history of allergies, surgery, or perineal trauma. In clinical examination, no deviations from normal were found.

Urine for culture was taken and the result was negative. The patient underwent urethrography and micturition cystourethrogram, which had shown angulation in the proximal part of anterior urethra. Perineum ultrasonography (US) showed cystic structure, probably variation of Cowper's gland. Pelvis MRI (Fig. 1) showed cystic formation, measuring $67 \times 34 \times 32 \mathrm{~mm}$, on the basis of penis inside corpus spongiosum that was connected to the Cowper's gland on the right side at the level of urogenital diaphragm through $4 \mathrm{~cm}$ long channel. Preoperatively uroflowmetry was performed, which showed obstruction. Urodynamic studies were not performed.

Owing to severe pain, the patient was admitted to the ward. Surgical treatment was indicated. He was operated on under general anesthesia. Endoscopic approach was chosen and unroofing with holmium YAG laser was done (Fig. 2). Calculase II $20 \mathrm{~W}$ holmium laser Storz ${ }^{\circledR}$ was used. Cystoscope with Albarran deflector from the same manufacturer was used. Through urethral catheter, $230 \mu \mathrm{m}$ laser fiber was inserted. Laser settings were as follows: energy $0.8 \mathrm{~J}$, frequency $6 \mathrm{~Hz}$, and power $4.8 \mathrm{~W}$. The distance from syringocele to the sphincter was $\sim 1 \mathrm{~cm}$. At the end of the procedure, urinary catheter $16 \mathrm{~F}$ was inserted, the urine was clean. Postoperatively the patient received two doses of cephamezine. He was discharged from the hospital on the first postoperative day; the urinary catheter was left in situ. Two days later, he returned to our ED because of pain during defecation. He did not report having blood in the urine. He was constipated. In the clinical presentation, abdomen was painful on palpation suprapubically. Urinary catheter was functional. Blood was taken for laboratory investigationscomplete blood count, electrolytes, and C-reactive protein were within normal limits. The patient received analgesia (paracetamol) and was released for home treatment. He was seen 2 weeks later on postoperative examination. Urinary catheter was removed. On postoperative follow-ups, the patient did not report any difficulties; he was asymptomatic, without signs of urinary incontinence, and satisfied with the surgical procedure. Control pelvis MRI (Fig. 3) showed normal urethra.

\section{Discussion and Literature Review}

Cowper's syringocele is usually diagnosed among children, although there are rare cases reporting this condition in the adult population. ${ }^{3}$ Our patient was symptomatic since age of 15 and was diagnosed at age of 17 . In the meantime he was treated for UTI.

Etiology of this condition is not clear; it can be congenital or acquired. ${ }^{5}$ Traditionally four types of syringocele are described. ${ }^{1,3}$ Our patient had type III syringocele according to Maizels classification. Recent reviews suggest that syringocele should be grouped based on the configuration of the duct's orifice to the urethra. It is proposed that closed (obstructive) syringocele has cystically occluded ducts. Because of dilation against urethra, obstructive symptoms develop. In contrast, open (nonobstructive) syringocele has continuous lumen that connects urethra and cystic ducts. Urethral saccule is mimicked and postvoid dribbling is present. $^{3}$

Nonobstructive syringocele presents with UTI, fever, and/or urinary incontinence. Obstructing syringocele causes obstructive voiding symptoms or US evidence of obstruction. Symptoms such as hematuria, dysuria, frequency, and recurrent UTI are associated with both categories. ${ }^{3}$

Diagnostic evaluation starts with voiding history. Perineum US is useful since it can detect closed cystic lesions in the anatomic region of Cowper's gland. It can also detect open syringocele. Diagnosis is confirmed with antegrade and retrograde uretherography. Additional information could be gained with cystouretheroscopy, urodynamic studies, CT scan, or MRI, depending on availability of different diagnostic modalities. ${ }^{3}$ Perineum US in our case showed cystic formation of Cowper's gland, diagnosis was confirmed with pelvis MRI. We performed uroflowmetry preoperatively that showed an obstructive curve; we found that the maximum flow rate $(\mathrm{Qmax})$ was significantly diminished relative to

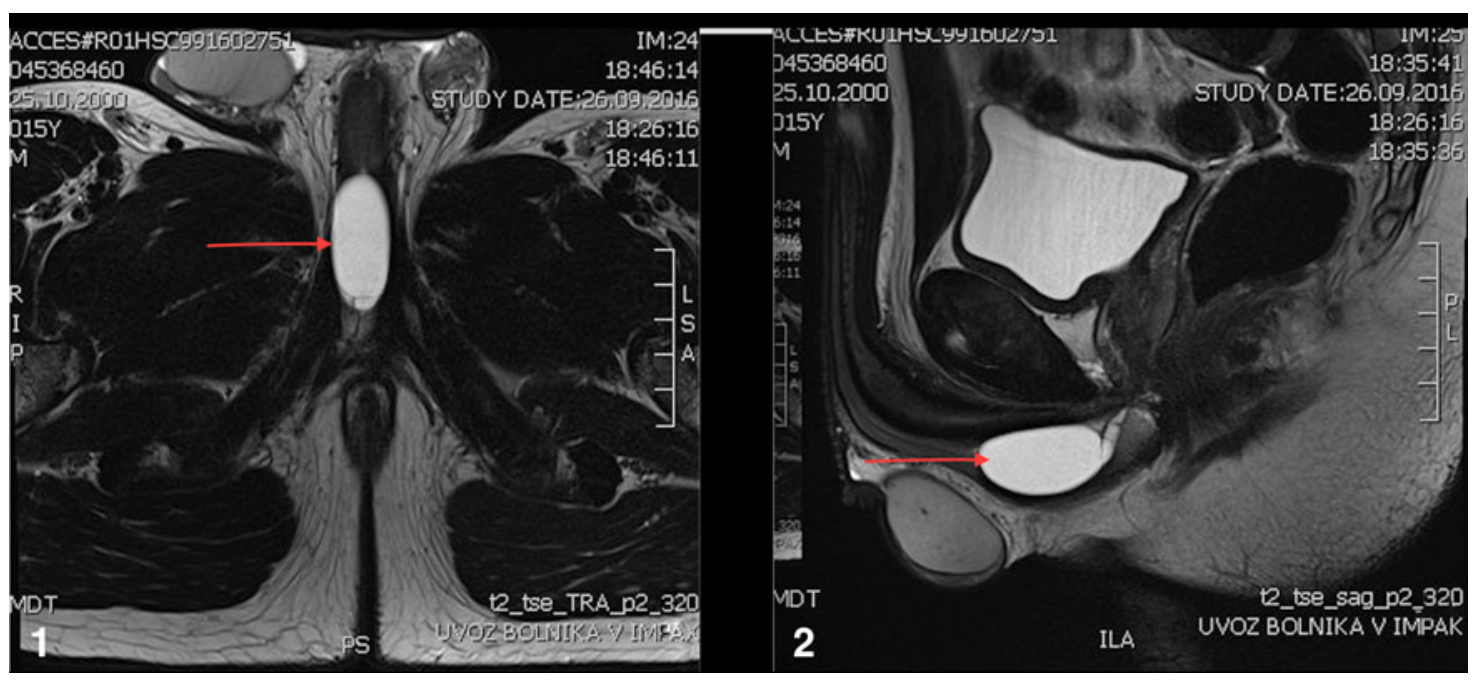

FIG. 1. Preoperative pelvis MRI. (1) Transverse section. (2) Sagittal section. Red arrow points at Cowper's syringocele. 
FIG. 2. Unroofing Cowper's syringocele. (1) Endoscopic identification of syringocele. (2) Use of holmium YAG laser for unroofing. (3) Unroofing Cowper's syringocele. (4) Endoscopic view after completion of unroofing.
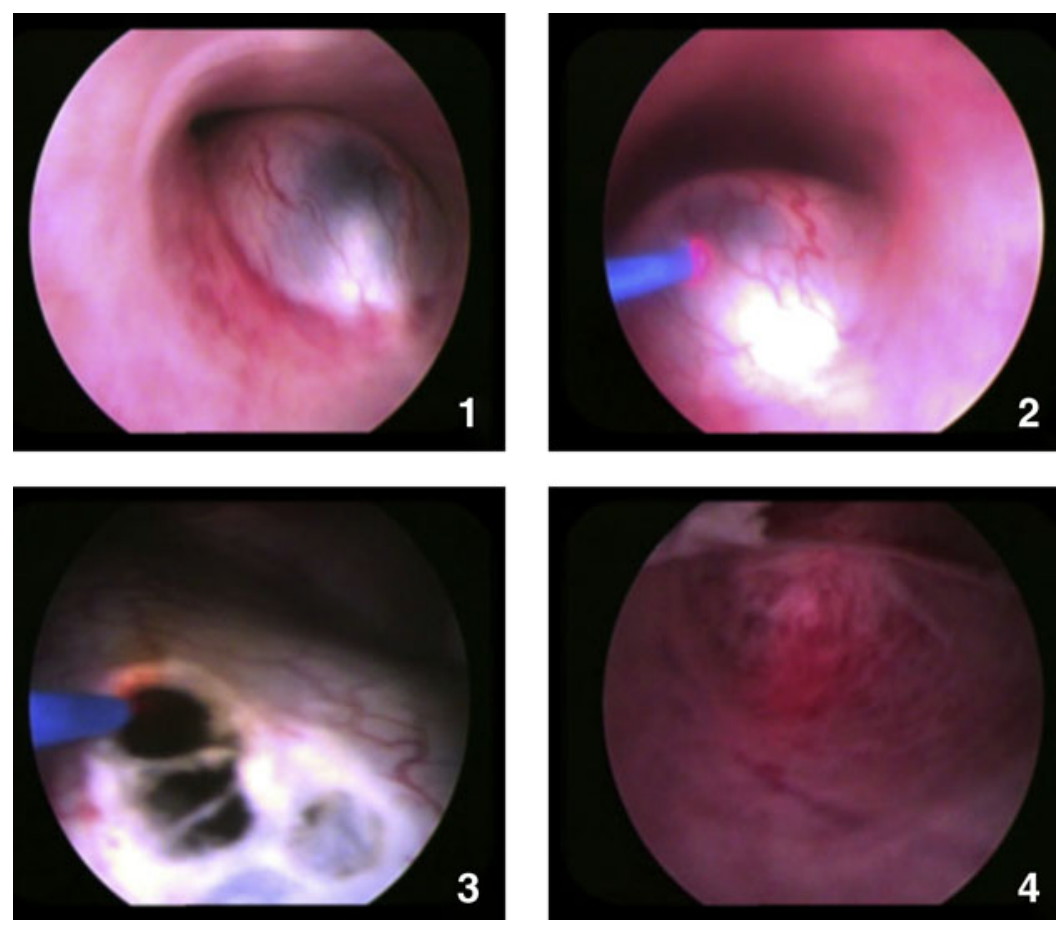

age-matched controls. After the surgical procedure, the curve was normal, with Qmax of $24 \mathrm{cc} / \mathrm{sec}$.

Treatment of syringocele can be conservative (observation) or surgical (endoscopic or open surgery). Asymptomatic syringocele can be observed, and if symptoms are not relieved, surgical treatment is indicated. Some authors have described several cases whose symptoms resolved on their own-effective treatment of UTI, with no surgical intervention. $^{3}$

Endoscopic intervention has become the preferred treatment for symptomatic syringocele. ${ }^{3,5}$ Unroofing the cyst or marsupialization is a relatively simple and effective way of treatment, using cold knife or holmium YAG laser. It can be used for both open and closed syringocele. ${ }^{3}$ Our patient was treated with endoscopic unroofing with holmium YAG laser.
The procedure was performed without complications, and postoperative recovery was without major complications.

Open procedures are indicated when endoscopic treatment fails or if syringocele presents as a large perineal mass. ${ }^{3}$ Different open approaches may be used, such as transperineal ligation of Cowper's gland, open excision, and urethral repair. ${ }^{3,5}$

\section{Conclusion}

Although a rare finding, Cowper's syringocele should be considered in adult patients presenting with irritative and/ or obstructing symptoms. Noninvasive diagnostic tools such as perineum US are favored. For further evaluation, MRI of the pelvis, cystoscopy, urodynamic studies, and cystourethrography are used. Most cases require surgical treatment.
FIG. 3. Postoperative pelvis MRI. (1) Transverse section. (2) Sagittal section.

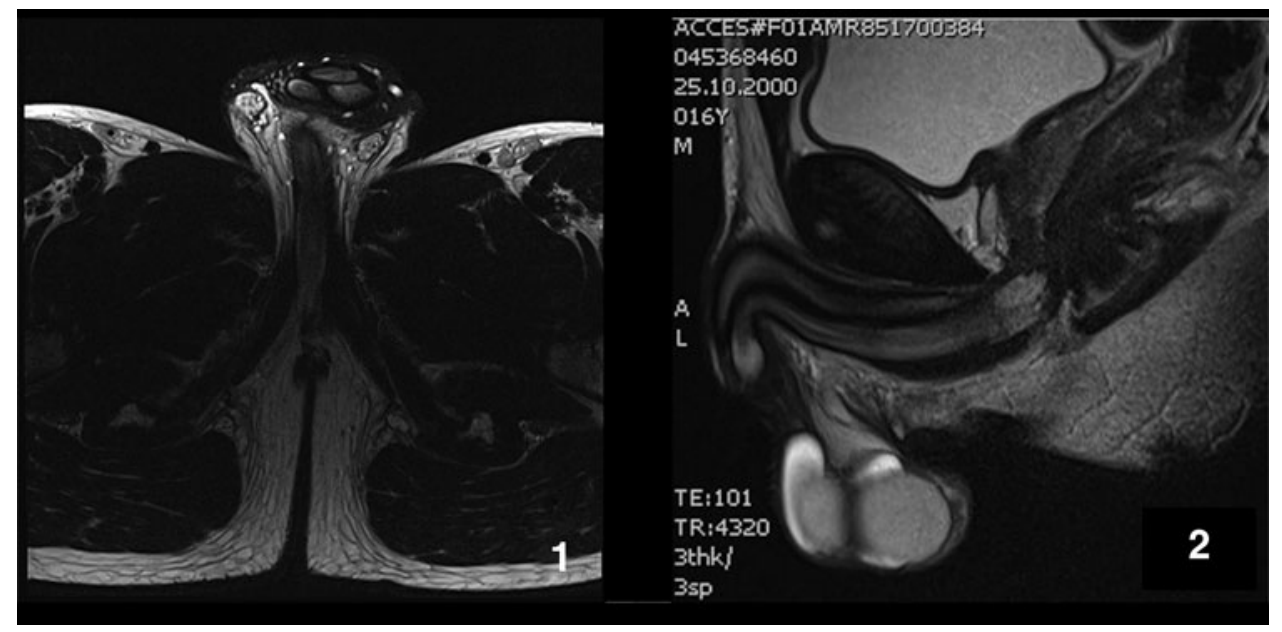


Endoscopic treatment is preferred over open surgery. Open surgery is reserved for large masses or when endoscopic treatment fails. Endoscopic unroofing is a preferred technique. Data about success and satisfaction rate are promising.

\section{Disclosure Statement}

No competing financial interests exist.

\section{References}

1. Shaw MBK, Cole O, Terry TR. Cowper's syringocele causing painful hematuria in an adult. ScientificWorldJournal 2004;4: 308-310.

2. Awakura Y, Nonomura M, Fukuyama T. Cowper's syringocele causing voiding disturbance in an adult. Int $\mathrm{J}$ Urol 2000:340-342.

3. Melquist J, Sharma V, Sciullo D, McCaffrey H, Khan SA. Current diagnosis and management of syringocele: a review. Int Braz J Urol 2010;36:3-9.

4. Maizels M, Stephens FD, King LR, Firlit CF. Cowper's syringocele: A classification of dilatations of Cowper's gland duct based upon clinical characteristics of 8 boys. J Urol 1983;129:111-114.

5. Surana S, Elshazly M, Allam A, Jayappa S, AlRefai D. A case of giant Cowper's gland syringocele in an adult male patient. Case Rep Urol 2015;2015:682042.
Address correspondence to: Simon Hawlina, MD Department of Urology

University Medical Centre Ljubljana Zaloška 7

Ljubljana 1000

Slovenia

E-mail: simonha2000@gmail.com

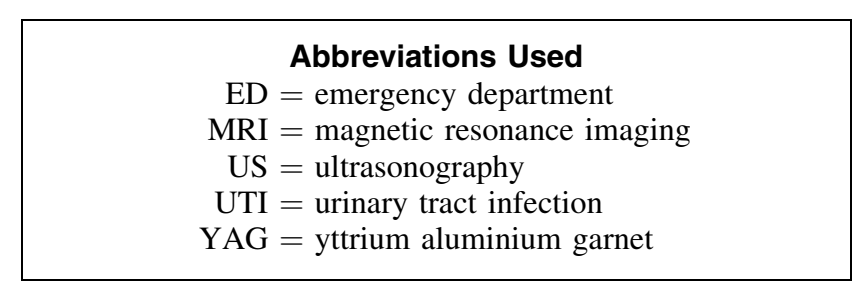

Cite this article as: Taskovska M, Hawlina S (2017)

Cowper's syringocele in adolescent male: case report, Journal of Endourology Case Reports 3:1, 130-133, DOI: $10.1089 /$ cren.2017.0086. 